\title{
Kidney Transplant Recipients' Weight Change and their Behaviors and Attitudes Related to Diet and Exercise
}

\author{
Kathryn Nutting ${ }^{1}$, Julia Naman ${ }^{1}$, Nia S Mitchell ${ }^{2}$, Michelle Josephson ${ }^{3,4}$, and Milda R Saunders ${ }^{4,5, *}$ \\ ${ }^{1}$ Pritzker School of Medicine, University of Chicago, Chicago, IL, United States \\ ${ }^{2}$ General Internal Medicine, Duke University, Durham, NC, United States \\ ${ }^{3}$ Nephrology, University of Chicago Medicine, Chicago, IL, United States \\ ${ }^{4}$ Transplant Institute, University of Chicago Medicine, Chicago, IL, United States \\ ${ }^{5}$ General Internal Medicine, University of Chicago Medicine, Chicago, IL, United States
}

*Corresponding author: Milda R Saunders, General Internal Medicine, University of Chicago Medicine, MC2007, Chicago, IL 60637, United States, Phone: (773) 702-5941; E-mail: msaunders@uchicago.edu

Received: 17 Mar, 2021 | Accepted: 20 Apr, 2021 | Published: 28 Apr, 2021

Citation: Nutting K, Naman J, Mitchell NS, Josephson M, Saunders MR (2021) Kidney Transplant Recipients' Weight Change and their Behaviors and Attitudes Related to Diet and Exercise. Int J Nephrol Kidney Fail 7(1): dx.doi.org/10.16966/2380-5498.208

Copyright: (C) 2021 Nutting K, et al. This is an open-access article distributed under the terms of the Creative Commons Attribution License, which permits unrestricted use, distribution, and reproduction in any medium, provided the original author and source are credited.

\section{Abstract}

Background: Weight gain after kidney transplant has been demonstrated to have adverse effects on allograft function and longevity. We sought to determine both the prevalence of post-transplant weight gain and factors associated with weight gain.

Methods: We surveyed post-transplant patients about diet and physical activity associated with post-transplant weight changes, and conducted a retrospective chart review to determine post-transplant weight changes of a larger post-transplant cohort. We used cross-tabulation, bivariable and multivariable logistic regression to examine whether there were any associations between important demographic and clinical categories and weight change.

Results: Most of the surveyed patients $(n=40)$ were in the early post-transplant phase $(65 \%$ of patients $<6$ months post-transplant, and $87.5 \%$ less than 2 years post-transplant). Of those surveyed with a recorded weight ( $n=38), 34 \%$ lost weight, $42 \%$ maintained their weight, and $24 \%$ had gained weight. Nearly all $(97 \%)$ surveyed patients reported exercise was important to the health of their kidneys, although only $43 \%$ reported exercising more than once a week post-transplant. Those who did exercise regularly were significantly more likely to have post-transplant weight loss ( $\mathrm{p}=0.01$ ). In a larger chart review $(n=100), 45 \%$ of patients gained weight by one-year post-transplant. Weight gain at one year was associated with age less than 50 and weight gain at 3 months (both $p>0.05$ ).

Discussion: Our findings suggest that early, intensive lifestyle management programs post-transplant can help prevent weight gain. In addition, post-transplant providers can focus counseling on implementing and maintaining healthy behavior change, rather than explaining its importance.

Keywords: Kidney transplant; Post-transplant; Weight change; Exercise

\section{Background}

Weight gain after a kidney transplant negatively affects the recipient's health and may impair allograft function and longevity $[1,2]$. Post-transplant weight gain can lead to diabetes, hypertension, and excessive allograft hypertrophy due to increased body mass [2,3]. Weight gain also contributes to cardiovascular disease, one of the leading causes of death after kidney transplantation [4]. Weight gain is a major concern for kidney transplant recipients with as many as $50 \%$ of transplant recipients gaining weight [5-7].

While kidney transplant recipients face challenges similar to the general population regarding weight gain, they also face unique challenges related to their post-transplant status. Anti-rejection medication regimens, which often include corticosteroids, can increase fluid retention and body fat distribution. After the transplant, patients may have increased caloric intake due to increased appetite combined with reduced dietary restrictions [8]. In addition, they may limit physical activity due to prior inactivity, fear of injuring their allograft and unclear post-surgical activity limitations $[8,9]$.

Thus, we sought to examine the extent of weight gain in the posttransplant cohort in an urban, academic medical center. Building on prior work, we sought to determine which factors were associated with post-transplant weight gain in our patient cohort and to better understand patient behaviors and attitudes surrounding diet and exercise to identify possible early interventions to help patients with weight management after kidney transplantation. 


\section{Design/Methods}

This study consists of both a cross-sectional survey and a retrospective chart review of post-transplant patients at a single, urban Midwest transplant center. This study was approved by the Institutional Review Board (IRB \#17-0399).

\section{Survey and population}

Patients were enrolled over five weeks from July 2017 to August 2017 at the University of Chicago renal transplant follow-up clinic. Patients were asked to participate if they were over the age of 18 , received a kidney-only transplant, and appeared in the post-transplant clinic for follow-up. Patients who did not speak English had received a combined kidney-pancreas transplant, or had weight loss surgery before or after transplant were excluded.

Surveys were distributed to patients in the post-transplant clinic. Most surveys were self-administered; however, per patient request, surveys could be administered verbally. Less than 5 surveys were verbally administered. Weight variables were collected from the recorded weight for the visit, as well as patient-reported weight on the survey. Patient demographic variables including age, sex, race and ethnicity were abstracted from the chart.

The survey consisted of 46 multiple choice questions and four short answer questions to evaluate patients' attitudes and behaviors regarding weight, physical activity, and nutrition, counseling about diet or exercise, and interest in support programs (see Appendix). Survey questions were developed based on previous literature $[8,10,11]$.

\section{Chart review}

The chart review examined a cohort of 100 patients who received a kidney transplant between January 2011 and December 2015, chosen by a random number generator from a total list of 195 patients seen in the post-transplant clinic.

For the chart review, the selected patients' medical record numbers were used to look up charts in the electronic medical record (Epic system). Charts were reviewed for age, sex, race/ethnicity, weight and BMI at the date of transplant, 3 months and 1-year follow-up. If an exact 3 month or 1-year follow-up appointment was not recorded, the next closest appointment date before or after was used. We defined 3 -month appointments as on-time if they occurred at 90+14 days, and 1 -year follow-up appointments as on-time if they occurred at $365+30$ days.

\section{Variables}

Our primary outcome of interest was weight change. For Chart review data, weight change was calculated at 3 months and 1 year. Weight change was calculated by subtracting weight at either 3 months or one-year follow-up from the weight on the day of the transplant, respectively, then dividing by the initial post-transplant weight. Weight change considered clinically significant was a 5 percent or greater change in either direction and was classified into the following categories: weight gain, weight loss, and no change. Patient weight was classified as underweight, normal weight, overweight, obese according to BMI category [12]. The race was classified as black, white, or other. Age was categorized as less than 50 years old and 50 years old or greater, based on the mean age of the sample. Time since transplant was categorized as less than 6 months, 6 months to 2 years, or greater than 2 years, based on prior literature $[10,13]$.

\section{Data analysis}

Statistical tests were completed using STATA software version 14 .
Chi-square tests were run to assess for associations. For survey data, we used cross-tabulation; bivariable and multivariable logistic regression to examine whether there were any associations between important demographic, clinical categories and weight change. Sensitivity analyses were conducted with chart review patients who were on time for the 3 months and 1-year follow-up visits. Statistical significance was considered $\mathrm{P}<0.05$.

\section{Results}

\section{Survey sample}

The survey cohort included 40 kidney transplant recipients, with a mean age of $48.7 \pm 11.8$. Fourteen (35\%) of the participants were female and 27 (67.5\%) were black. Twenty-six (65\%) were surveyed within the first six months of transplant and nine (22.5\%) were surveyed between six months and 2 years of transplant (Table 1).

\section{Weight changes}

For the survey, 38 of the 40 respondents had a weight recorded at the time of transplant allowing for weight change to be calculated. Thirteen people lost weight (34\%), 16 (42\%) maintained their weight, and 9 (24\%) gained weight. Overall, $32 \%$ of patients reported being happy with their weight, and $48 \%$ of patients reported wanting to lose weight (Table 2). Weight change was significantly associated with patient self-reported exercising; individuals with weight loss were significantly more likely to report exercising $(\mathrm{p}<0.05)$ (Table 3$)$.

Table 1: Participant characteristics (Survey and Chart Review).

\begin{tabular}{|l|c|c|}
\hline & $\begin{array}{c}\text { Survey Data } \\
\text { (N = 40) }\end{array}$ & $\begin{array}{c}\text { Chart Review } \\
\text { Data (N=100) }\end{array}$ \\
\hline Sex [n (\%)] & & \\
\hline Male & $26(65)$ & $64(64)$ \\
\hline Female & $14(35)$ & $36(36)$ \\
\hline Mean Age [m (SD)] & $48.7(11.8)$ & $50.4(12.6)$ \\
\hline Race [n (\%)] & & \\
\hline Black & $27(67.5)$ & $56(56)$ \\
\hline White & $12(30)$ & $35(35)$ \\
\hline Other & $1(2.5)$ & $9(9)$ \\
\hline Time Since Transplant at Survey [n (\%)] & & \\
\hline$<6$ months & $26(65)$ & - \\
\hline 6 months-2 years & $9(22.5)$ & - \\
\hline$>2$ years & $5(12.5)$ & - \\
\hline Patient Weight at Survey [n (\%)] & & \\
\hline Underweight & $0(0)$ & - \\
\hline Normal Weight & $15(37.5)$ & - \\
\hline Overweight & $8(20)$ & - \\
\hline Obese & $17(42.5)$ & - \\
\hline Patient Weight at Date of Transplant & & \\
\hline Underweight & - & $2(2)$ \\
\hline Normal Weight & $12(32)$ & $27(27)$ \\
\hline Overweight & $7(18)$ & $35(35)$ \\
\hline Obese & $19(50)$ & $36(36)$ \\
\hline Weight Change since Transplant [n (\%)] & & After 1 Year \\
\hline Lost Weight & $13(34)$ & $5(5)$ \\
\hline No Change & $16(42)$ & $50(50)$ \\
\hline Gained Weight & $9(24)$ & $45(45)$ \\
\hline Weight gan Was consing & \\
\hline
\end{tabular}

Weight gain was considered to be an increase in weight by $5 \%$ or greater and weight loss was considered to be a decrease of $5 \%$ or more. 
Table 2: Survey results.

\begin{tabular}{|c|c|}
\hline \multicolumn{2}{|l|}{ Has your weight changed since transplant? } \\
\hline No & $6(15)$ \\
\hline Yes, gained weight & $17(42)$ \\
\hline Yes, lost weight & $17(42)$ \\
\hline \multicolumn{2}{|l|}{ Are you happy with your current weight? } \\
\hline Yes, I am happy with my current weight & $13(32.5)$ \\
\hline No, would like to lose weight & $19(47.5)$ \\
\hline No, would like to gain weight & $8(20)$ \\
\hline \multicolumn{2}{|l|}{$\begin{array}{l}\text { Do you think your weight is important to the health of } \\
\text { your kidney or overall health? }\end{array}$} \\
\hline Yes, to kidney and overall health & $34(87.2)$ \\
\hline Yes, to kidney health only & $1(2.6)$ \\
\hline Yes, to overall health but it does not affect my kidney & $2(5.1)$ \\
\hline No, it is not important to either & $2(5.1)$ \\
\hline \multicolumn{2}{|l|}{$\begin{array}{l}\text { Did you receive counseling on healthful eating after your } \\
\text { transplant before discharge? }\end{array}$} \\
\hline Yes, I found it helpful & $30(77.0)$ \\
\hline Yes, but it was not helpful & $3(7.7)$ \\
\hline No, I did not receive nutrition counseling & $6(15.4)$ \\
\hline \multicolumn{2}{|l|}{$\begin{array}{l}\text { Has someone on your healthcare team discussed } \\
\text { nutrition during follow up visits? }\end{array}$} \\
\hline Yes, at several visits & $25(62.5)$ \\
\hline Yes, at one visit & $7(17.5)$ \\
\hline No, not at all & $6(15)$ \\
\hline Unsure & $2(5)$ \\
\hline \multicolumn{2}{|l|}{ Do you eat more now than before your transplant? } \\
\hline Yes, I eat more now & $15(37.5)$ \\
\hline No, I eat the same as I did before my transplant & $18(45)$ \\
\hline No, I eat less than before my transplant & $7(17.5)$ \\
\hline \multicolumn{2}{|l|}{$\begin{array}{l}\text { Has removal of dietary restrictions since your transplant } \\
\text { changed how you eat? }\end{array}$} \\
\hline Yes, my diet has changed significantly since transplant & $12(30)$ \\
\hline Yes, my diet has changed slightly since transplant & $20(50)$ \\
\hline No, my diet is the same as before transplant & $8(20)$ \\
\hline \multicolumn{2}{|l|}{ Do you exercise? } \\
\hline Yes, 5 or more times a week & $8(20)$ \\
\hline Yes, 2-4 times a week & $9(22.5)$ \\
\hline Yes, less than once a week & $5(12.5)$ \\
\hline No, but I plan to begin an exercise program & $12(30)$ \\
\hline No, and I do not plan to begin an exercise program & $0(0)$ \\
\hline I have not been cleared for post-transplant exercise yet & $6(15)$ \\
\hline \multicolumn{2}{|l|}{$\begin{array}{l}\text { Do you usually consider exercise to be a factor in the } \\
\text { health of your kidneys? }\end{array}$} \\
\hline Yes, very important & $31(77.5)$ \\
\hline Yes, moderately important & $8(20.0)$ \\
\hline No, not important & $1(2.5)$ \\
\hline \multicolumn{2}{|l|}{$\begin{array}{l}\text { Did anyone on your healthcare team talk to you about } \\
\text { exercise after your transplant? }\end{array}$} \\
\hline $\begin{array}{l}\text { Yes, I had excellent counseling about exercising after } \\
\text { transplant }\end{array}$ & $10(25.6)$ \\
\hline $\begin{array}{l}\text { Yes, I received some information about exercising after } \\
\text { transplant }\end{array}$ & 14 (35.9) \\
\hline $\begin{array}{l}\text { Yes, it was mentioned but I did not receive adequate } \\
\text { information about it }\end{array}$ & 7 (17.9) \\
\hline No, exercising after transplant was not discussed & $8(20.5)$ \\
\hline \multicolumn{2}{|l|}{ If yes, did you find exercising counseling helpful? } \\
\hline $\begin{array}{l}\text { Yes, it motivated me to exercise or informed me of what I } \\
\text { should be doing }\end{array}$ & $26(66.7)$ \\
\hline $\begin{array}{l}\text { No, it did not motivate me or help me exercise after } \\
\text { transplant }\end{array}$ & $6(15.4)$ \\
\hline No one talked to me about exercise & 7 (17.9) \\
\hline
\end{tabular}

Table 3: Survey-Weight change by patient characteristics and selfreported behavior.

\begin{tabular}{|c|c|c|c|c|c|}
\hline & $\begin{array}{c}\text { Lost } \\
\text { Weight (\%) }\end{array}$ & $\begin{array}{l}\text { Maintained } \\
\text { Weight (\%) }\end{array}$ & $\begin{array}{c}\text { Gained } \\
\text { Weight (\%) }\end{array}$ & P-Value & Chi-Sq \\
\hline \multicolumn{6}{|l|}{ Age } \\
\hline$<50$ & 29 & 44 & 28 & \multirow{2}{*}{0.63} & \multirow{2}{*}{0.92} \\
\hline$\geq 50$ & 41 & 41 & 18 & & \\
\hline \multicolumn{6}{|l|}{ Race } \\
\hline Black & 27 & 46 & 27 & \multirow{2}{*}{0.34} & \multirow{2}{*}{1.96} \\
\hline White/Other & 54 & 33 & 17 & & \\
\hline \multicolumn{6}{|l|}{ Sex } \\
\hline Male & 28 & 44 & 28 & \multirow{2}{*}{0.48} & \multirow{2}{*}{1.46} \\
\hline Female & 46 & 38 & 15 & & \\
\hline \multicolumn{6}{|l|}{ Exercise } \\
\hline No & 6 & 67 & 28 & \multirow{2}{*}{$0.01 *$} & \multirow{2}{*}{9.32} \\
\hline Yes & 50 & 35 & 15 & & \\
\hline \multicolumn{6}{|l|}{$\begin{array}{l}\text { BMI category } \\
\text { at transplant }\end{array}$} \\
\hline $\begin{array}{l}\text { Normal } \\
\text { weight }\end{array}$ & 42 & 50 & 8 & \multirow{3}{*}{0.19} & \multirow{3}{*}{6.09} \\
\hline Overweight & 14 & 29 & 57 & & \\
\hline Obese & 37 & 42 & 21 & & \\
\hline \multicolumn{6}{|l|}{$\begin{array}{l}\text { BMI category } \\
\text { at Survey }\end{array}$} \\
\hline $\begin{array}{l}\text { Normal } \\
\text { weight }\end{array}$ & 21 & 43 & 36 & \multirow{3}{*}{0.66} & \multirow{3}{*}{2.44} \\
\hline Overweight & 43 & 43 & 14 & & \\
\hline Obese & 41 & 41 & 18 & & \\
\hline
\end{tabular}

*Statistically significant finding, $p<0.05$.

\section{Surveyed behaviors and attitudes}

Fifteen (38\%) people reported eating more after transplant, while 7 (18\%) reported eating less after transplant (Table 2). Thirty-two (80\%) reported a dietary change due to reduced dietary restrictions. Twentytwo patients (55\%) reported any exercise after transplant, with eight (20\%) reporting exercising at least five times a week and nine $(23 \%)$ reporting exercising 2-4 times a week. Eighteen participants (45\%) were confident in the types and amount of exercise they were doing. Thirty-five people (90\%) believed maintaining a healthy weight was important to the health of their kidneys and $98 \%$ of patients believed exercise was important to the health of their kidneys. Nearly $85 \%$ of patients reported receiving post-transplant counseling on healthy eating, and $91 \%$ of those found it helpful. About $79 \%$ of patients received post-transplant counseling on exercise; $67 \%$ of those reported that it was helpful. The most common intervention types people felt would be helpful to supporting healthy dietary changes were mobile or online information sources $(46 \%)$ and working with a dietician (48\%). For increasing physical activity, the most common intervention participants felt would be helpful was having a physical activity partner (55\%).

\section{Chart review sample}

The chart review included 100 patients with a mean age of $50.4 \pm$ 12.6. Thirty-six (36\%) of participants were female and 56 (56\%) were black. At the time of transplant, 2\% were underweight, $27 \%$ were normal weight, $35 \%$ were overweight and $36 \%$ were obese (Table 1 ).

At three months, $23 \%$ of patients had lost weight, $54 \%$ had no weight change, and $23 \%$ gained weight. At one-year follow-up $5 \%$ of patients 
lost weight, $50 \%$ had no weight change, and $45 \%$ had gained weight. Forty-eight percent of patients were obese, $33 \%$ were overweight, and $19 \%$ of patients had a normal BMI. There was no significant association between the pre-transplant weight category and post-transplant weight change (Table 4). Weight change was significantly associated with age; patients over age 50 were more likely to have lost or maintained weight at one year, compared to patients under $50(\mathrm{chi} 2=6.7, \mathrm{p}<0.05)$. Patients who gained weight at three months were significantly more likely to have gained weight at one year (extended McNemar's chi2 $=88.57$, $\mathrm{p}<0.05)$. In bivariable and multivariable analysis, weight gain at 3 months is significantly associated with weight gain at 1 year $(\mathrm{OR}=6.9$ and $\mathrm{OR}=6.3, \mathrm{p}<0.05)($ Appendix Table 1$)$.

We conducted a sensitivity analysis on patients who were on time (within range) for the 3 months and 1-year follow-up visits. At 3 months, 80 patients had an on-time visit, and at 1 year 80 patients had an on-time visit; 65 patients had both on-time follow-up visits. The 65 patients in the subsample had a mean age of $50.2 \pm 12.6$. Twentytwo $(34 \%)$ of participants were female and $38(61 \%)$ were black. At the time of transplant, $3 \%$ were underweight, $28 \%$ were normal weight, $32 \%$ were overweight and $37 \%$ were obese. At one year $54 \%$ had maintained weight and $40 \%$ had gained weight. Weight gain was not significantly associated with age over $50(\mathrm{chi} 2=4.1, \mathrm{p}=0.13)$. Patients who gained weight at three months were significantly more likely to have gained weight at one year (extended McNemar's chi2 $=20.2$, $\mathrm{p}<0.05$ ), results not shown. In bivariable analysis, weight gain at 3 months is significantly associated with weight gain at 1 year $(\mathrm{OR}=3.60$, $\mathrm{p}<0.05)$. In multivariable analysis, weight gain at 3 months is no longer statistically significant $(\mathrm{OR}=3.46, \mathrm{p}<0.58)$ (Appendix Table 2$)$.

Table 4: Chart Review-Weight change at one year by demographics.

\begin{tabular}{|c|c|c|c|c|c|}
\hline & \begin{tabular}{|c|} 
Lost \\
Weight (\%)
\end{tabular} & $\begin{array}{l}\text { Maintained } \\
\text { Weight (\%) }\end{array}$ & \begin{tabular}{|c|} 
Gained \\
Weight (\%)
\end{tabular} & P-Value & Chi-Sq \\
\hline \multicolumn{6}{|l|}{ Age } \\
\hline$<50$ & 0 & 46 & 54 & \multirow{2}{*}{$0.04 *$} & \multirow{2}{*}{6.66} \\
\hline$\geq 50$ & 10 & 54 & 37 & & \\
\hline \multicolumn{6}{|l|}{ Race } \\
\hline Black & 4 & 53 & 44 & \multirow{3}{*}{0.07} & \multirow{3}{*}{9.01} \\
\hline White & 8 & 50 & 42 & & \\
\hline Other & 0 & 100 & 0 & & \\
\hline \multicolumn{6}{|l|}{ Sex } \\
\hline Male & 5 & 53 & 42 & \multirow{2}{*}{0.71} & \multirow{2}{*}{0.69} \\
\hline Female & 6 & 44 & 50 & & \\
\hline \multicolumn{6}{|l|}{$\begin{array}{l}\text { BMI category } \\
\text { at transplant }\end{array}$} \\
\hline Underweight & 0 & 0 & 100 & \multirow{4}{*}{0.78} & \multirow{4}{*}{0.78} \\
\hline Normal weight & 4 & 48 & 48 & & \\
\hline Overweight & 6 & 56 & 38 & & \\
\hline Obese & 6 & 49 & 49 & & \\
\hline \multicolumn{6}{|l|}{$\begin{array}{l}\text { Weight } \\
\text { change } \\
\text { 3m post- } \\
\text { transplant }\end{array}$} \\
\hline Lost weight & 17 & 74 & 9 & \multirow{3}{*}{$<0.01^{*}$} & \multirow{3}{*}{$88.57 * *$} \\
\hline $\begin{array}{l}\text { Maintained } \\
\text { weight }\end{array}$ & 0 & 55 & 45 & & \\
\hline Gained weight & 4 & 17 & 78 & & \\
\hline
\end{tabular}

*Statistically significant finding, $\mathrm{p}<0.05 .{ }^{* *}$ Using extended McNemar's Chi-Sq
Appendix Table 1: Chart Review-Odds of Weight Gain at One year (Entire Sample $n=100$ ).

\begin{tabular}{|l|c|c|}
\hline \multicolumn{1}{|c|}{ Variable } & $\begin{array}{c}\text { Bivariable (OR, 95\% } \\
\text { CI) }\end{array}$ & $\begin{array}{c}\text { Multivariable (OR, } \\
\text { 95\% Cl) }\end{array}$ \\
\hline Female & $1.37(0.60,3.11)$ & $1.31(0.52,3.31)$ \\
\hline $\begin{array}{l}\text { Age at Transplant, per 1 yr } \\
\text { increase }\end{array}$ & $0.96(0.93,0.99)^{*}$ & $0.96(0.92,0.99)^{*}$ \\
\hline $\begin{array}{l}\text { BMI at Transplant, per 1 } \\
\text { unit increase }\end{array}$ & $0.97(0.91,1.05)$ & $0.97(0.89,1.06)$ \\
\hline Weight Gain at 3 months & $6.92(2.31,20.76)^{*}$ & $6.29(2.04,19.38)^{*}$ \\
\hline
\end{tabular}

*Significant $p<0.05$. Outcome variable=weight increase $>5 \%$ at one year (yes/no).

Appendix Table 2: Chart Review-Odds of Weight Gain at One year with On-time Sample $(n=65)$.

\begin{tabular}{|l|c|c|}
\hline \multicolumn{1}{|c|}{ Variable } & $\begin{array}{c}\text { Bivariable (OR, 95\% } \\
\text { Cl) }\end{array}$ & $\begin{array}{c}\text { Multivariable (OR, } \\
\mathbf{9 5 \%} \text { Cl) }\end{array}$ \\
\hline Female & $1.40(0.50,3.98)$ & $1.38(0.43,4.34)$ \\
\hline $\begin{array}{l}\text { Age at Transplant, per 1 yr } \\
\text { increase }\end{array}$ & $0.96(0.93,1.01)$ & $0.96(0.92,1.01)$ \\
\hline $\begin{array}{l}\text { BMI at Transplant, per 1 unit } \\
\text { increase }\end{array}$ & $0.94(0.86,1.04)$ & $0.93(0.96,12.47)$ \\
\hline Weight Gain at 3 months & $3.6(1.04,12.42)^{*}$ & $3.46(0.96,12.47)$ \\
\hline
\end{tabular}

*Significant $p<0.05$. Outcome variable=weight increase $>5 \%$ at one year (yes/no).

\section{Discussion}

In this study of patients at a single urban medical center, we found that although the majority of patients maintained or lost weight after transplant, almost half (45\%) gained weight at one year. Of the surveyed sample, most of whom were less than 6 months post-transplant, about one-third had lost weight. Previous studies have found that kidney transplant is associated with weight gain and significant increases in body weight and BMI in the first post-transplant year, with more than $50 \%$ of patients gaining weight $[5,7,10]$. Weight gain after transplant has been correlated with reduced kidney function, indicating the importance of helping patients reach healthy body weight posttransplant [14]. We also found weight gain in the first 3 months was associated with increased weight at the end of one year. This highlights the importance of early, intensive counseling during the first posttransplant year to help patients avoid early weight gain.

The majority (80\%) of patients reported changes in eating habits due to the removal of dietary restrictions, suggesting the posttransplant period is a key intervention point for the development and maintenance of new dietary habits. Our findings are consistent with prior work that demonstrates post-transplant dietary changes $[6,15]$. A large proportion of participants reported eating the same or less after transplant; however, they may be eating more calorically dense food, giving the perception of not eating more while increasing energy intake [16]. Most participants reported receiving counseling on healthy eating which is encouraging.

Similar to other renal transplant patients studied, the majority of our patients are not meeting recommended levels of physical activity [17]. While 55\% of surveyed patients reported exercising after transplant, only $43 \%$ reported exercising at least two days a week. Those reporting no physical activity were significantly more likely to gain weight, suggesting that exercise may be an important 
factor in helping transplant patients prevents weight gain [18]. Most (79\%) patients reported receiving exercising counseling, with $67 \%$ of those report finding it helpful. Exercise counseling may need to be individualized so that patients know what exercises are appropriate and safe after transplant. In addition to counseling, patients may also benefit from referral to a post-transplant physical rehabilitation program or consulting with an exercise specialist. It is also important to address other barriers to exercise, including mobility limitations, fear of injuring the kidney, environmental factors, and low motivation [9].

Previous studies found patients on the transplant waitlist did not consider exercise to be a factor in the health of their kidneys [19]. Recent work has shown an association between exercise and slower post-transplant eGFR decline [20]. Nearly all (98\%) of our surveyed patients reported exercise was important to the health of their kidneys and $90 \%$ believed maintaining a healthy weight was important to the health of their kidneys. If patients are already aware of the importance of exercise and weight management, healthcare providers can focus their clinic time addressing specific physical activity goals and barriers.

When asked about preferences for lifestyle intervention programs, most patients reported online resources would be helpful and preferred. Directing patients to already available online resources related to healthy eating and exercising may provide quick access while more specific resources are created for transplant patients. It may also be helpful to distribute information sheets about healthy eating or beginning an exercise program in a post-transplant clinic. Additionally, structured exercise programs and renal rehabilitation programs, similar to cardiac and pulmonary rehabilitation programs, may benefit patients in the post-transplant period [21-23].

We also found that older age was associated with a lower likelihood of weight gain at one year. Our work is consistent with several other studies that have found that younger age at transplant is positively associated with post-transplant weight gain $[10,13,24,25]$. Potential reasons for lower weight gain in older adults may be due to lower steroid dosing post-transplant, having greater leisure time for meal preparation and exercise or greater adherence to medical recommendations for older patients [26]. Additional qualitative and quantitative work is needed to explore this association.

Limitations of this study include a relatively small sample size those surveyed skewed toward more recent transplants since those patients have more frequent post-transplant appointments. These patients are in a critical time where healthy habits can be developed to prevent weight gain later. Errors due to participants inaccurately remembering or reporting their behaviors during this one-time survey cannot be excluded. It was not possible to determine if weight change was due to fluid shifts, which is often expected post-transplant as newly functioning kidneys rid the body of excess water. For the chart review cohort, we were able to capture weight changes at 3 months and one year; however, we could not determine why those changes occurred. In addition, a large portion of the patients had either their threemonth or one-year follow-up visit outside of the prescribed range; however, findings were robust in analysis on the "on-time" subsample. Additionally, our sample is a younger, urban, predominately African American population so our results may not be generalizable to the post-transplant population overall.

Kidney transplant recipients face distinct challenges in addition to those the general population faces regarding weight gain. Future studies, building on prior work, should more closely evaluate dietary and physical activity habits through food journals and activity monitors to provide a more detailed look at patient behaviors impacting weight changes [27,28]. Prior work examining post-transplant-specific tailored exercise plans and diet guidelines has shown improvement in both patient-reported and clinical outcomes [21,28,29]. Further development and evaluation of a standardized counseling protocol for healthcare providers with post-transplant-specific exercise plans and diet guidelines may help to engage all patients with lifestyle counseling.

\section{Acknowledgments}

The authors do not have any conflicts of interest to disclose. This work was presented in abstract form at the Society of General Internal Medicine Midwest Regional Meeting in Chicago, IL in September 2018. Nutting K and Naman J were supported by the University of Chicago Pritzker School of Medicine Summer Research Program. The funders had no role in the design and conduct of the study; collection, management, analysis, and interpretation of the data; or preparation, review, and approval of the manuscript.

\section{Data Availability}

Data is available upon request.

\section{References}

1. Lafranca JA, IJermans JN, Betjes MG, Dor FJM (2015) Body mass index and outcome in renal transplant recipients: a systematic review and meta-analysis. BMC Med 13: 111.

2. Kwan JM, Hajjiri Z, Metwally A, Finn PW, Perkins DL (2016) Effect of the obesity epidemic on kidney transplantation: obesity is independent of diabetes as a risk factor for adverse renal transplant outcomes. PloS One 11: e0165712.

3. Pedrollo $E F$, Corrêa $C$, Nicoletto $B B$, Manfro $R C$, Leitão $C B$, et al. (2016) Effects of metabolic syndrome on kidney transplantation outcomes: a systematic review and meta-analysis. Transpl Int 29: 1059-1066.

4. Sgambat K, Clauss S, Moudgil A (2018) Cardiovascular effects of metabolic syndrome after transplantation: convergence of obesity and transplant-related factors. Clin Kidney J 11: 136-146.

5. Armstrong KA, Campbell SB, Hawley CM, Johnson DW, Isbel NM (2005) Impact of obesity on renal transplant outcomes. Nephrology (Carlton) 10: 405-413.

6. Cupples CK, Cashion AK, Cowan PA, Tutor RS, Wicks MN, et al. (2012) Characterizing dietary intake and physical activity affecting weight gain in kidney transplant recipients. Prog Transplant 22: 62-70.

7. Costa B, Moratelli L, Silva LB, Paiva ACM, Silva AN, et al. (2014) Body mass index in the first year after kidney transplantation. Transplant Proc 46: 1750-1752.

8. Stanfill A, Bloodworth R, Cashion A (2012) Lessons learned: experiences of gaining weight by kidney transplant recipients. Prog Transplant 22: 71-78.

9. Takahashi A, Hu SL, Bostom A (2018) Physical Activity in Kidney Transplant Recipients: A Review. Am J Kidney Dis 72: 433-443.

10. Cashion AK, Hathaway DK, Stanfill A, Thomas F, Ziebarth JD, et al. (2014) Pre-transplant predictors of one year weight gain after kidney transplantation. Clin Transplant 28: 1271-1278.

11. PACE+ Projects. PACE+Women- Measurement Questionnaire (MTM) (Baseline).

12. Centers for Disease Control and Prevention (CDC) (2020) About Adult Body Mass Index (BMI). CDC, USA. 
13. Majoni SW, Ullah S, Collett J, Hughes JT, McDonald S (2019) Weight change trajectories in Aboriginal and Torres Strait islander Australians after kidney transplantation: a cohort analysis using the Australia and New Zealand Dialysis and Transplant registry (ANZDATA). BMC Nephrol 20: 232.

14. Kim IK, Choi SH, Son S, Ju MK (2016) Early Weight Gain After Transplantation Can Cause Adverse Effect on Transplant Kidney Function. Transplant Proc 48: 893-896.

15. Sabbatini M, Ferreri L, Pisani A, Capuano I, Morgillo M, et al. (2019) Nutritional management in renal transplant recipients: A transplant team opportunity to improve graft survival. Nutr Metab Cardiovasc Dis 29: $319-324$

16. Zelle DM, Kok T, Dontje ML, Danchell El, Navis G, et al. (2013) The role of diet and physical activity in post-transplant weight gain after renal transplantation. Clin Transplant 27: E484-E490.

17. Dontje ML, de Greef MHG, Krijnen WP, Corpeleijn E, Kok T, et al. (2014) Longitudinal measurement of physical activity following kidney transplantation. Clin Transplant 28: 394-402.

18. Totti V, Fernhall B, Di Michele R, Todeschini P, Manna GL, et al. (2020) Longitudinal Analysis of Cardiovascular Risk Factors in Active and Sedentary Kidney Transplant Recipients. Medicina (Kaunas) 56: 183.

19. Sieverdes JC, Raynor PA, Armstrong T, Jenkins CH, Sox LR, et al. (2015) Attitudes and perceptions of patients on the kidney transplant waiting list toward mobile health-delivered physical activity programs. Prog Transplant 25: 26-34.

20. Masiero L, Puoti F, Bellis L, Lombardini L, Totti V, et al. (2020) Physical activity and renal function in the Italian kidney transplant population. Ren Fail 42: 1192-1204.

21. Rossi AP, Burris DD, Lucas FL, Crocker GA, Wasserman JC (2014) Effects of a renal rehabilitation exercise program in patients with CKD: a randomized, controlled trial. Clin J Am Soc Nephrol 9: 20522058.
22. Calella P, Hernández-Sánchez S, Garofalo $C$, Ruiz JR, Carrero JJ, et al. (2019) Exercise training in kidney transplant recipients: a systematic review. J Nephrol 32: 567-579.

23. Tzvetanov I, West-Thielke $P$, D'Amico $G$, Johnsen $M$, Ladik $A$, et al. (2014) A novel and personalized rehabilitation program for obese kidney transplant recipients. Transplant Proc 46: 3431-3437.

24. de Oliveira CMC, Moura ÁEF, Gonçalves L, Pinheiro LSF, Pinheiro Jr FML, et al. (2014) Post-transplantation weight gain: prevalence and the impact of steroid-free therapy. Transplant Proc 46: 1735-1740.

25. Clunk JM, Lin CY, Curtis JJ (2001) Variables affecting weight gain in renal transplant recipients. Am J Kidney Dis 38: 349-353.

26. Denhaerynck K, Dobbels F, Cleemput I, Desmyttere A, Schäfer-Keller $P$, et al. (2005) Prevalence, consequences, and determinants of nonadherence in adult renal transplant patients: a literature review. Transpl Int 18: 1121-1133.

27. Lorenz EC, Amer H, Dean PG, Stegall MD, Cosio FG, et al. (2015) Adherence to a pedometer-based physical activity intervention following kidney transplant and impact on metabolic parameters. Clin Transplant 29: 560-568.

28. Castle EM, Greenwood J, Chilcot J, Greenwood SA (2021) Usability and experience testing to refine an online intervention to prevent weight gain in new kidney transplant recipients. $\mathrm{Br} J$ Health Psychol 26: 232-255.

29. Orlandi G, Sofi F, Moscarelli L, Cirami L, Mancini S, et al. (2020) Exercise Prescription in Renal Transplant Recipients: From Sports Medicine Toward Multidisciplinary Aspects: A Pilot Study. J Funct Morphol Kinesiol 5: 10 